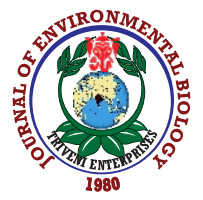

\title{
Studies on delignification in jute (Corchorus spp L.) fibre with promising lignin degrading bacterial isolates
}

\author{
S. Barai, L. Chattopadhyay and B. Majumdar* \\ Division of Crop Production, ICAR-Central Research Institute for Jute and Allied Fibres, Barrackpore-700 120, India \\ *Corresponding Author Email : bmajumdar65@gmail.com
}

\begin{abstract}
Aim: To investigate the reduction of lignin content in jute (Corchorus spp. L.) with promising lignin degrading bacterial isolates.

Methodology: Promising lignin degrading bacterial isolates were screened on the basis of potency index, MnP (manganese peroxidase) and LiP (lignin peroxidase) activities. Very efficient ligninolytic isolates were used for laboratory scale delignification trial and the resultant fibre was tested for lignin content, fibre strength and fineness. The efficient isolates were identified up to species level with Biolog Inc. based on the metabolic fingerprinting of the isolates.
\end{abstract}

Results: Out of 95 ligninolytic bactetial isolates, twenty isolates having potency index $>1.10$ on the basis of Azure-B dye degradation test were selected for enzyme assays. Five promising isolates ( $L 3$, L9, L10, L26 and L30) were selected for delignification trial on the basis of high MnP $\left(126-482 \mathrm{Ul}^{-1} \mathrm{~min}^{-1}\right)$, and LiP $\left(558.7-615.6 \mathrm{Ul}^{-1}\right.$ $\mathrm{min}^{-1}$ ) activities. The isolate L9 performed best among the five isolates and could reduce lignin content from 11.33 to $8.84 \%$ i.e. a reduction of $21.97 \%$ from the control. All the five isolates were identified as Bacillus spp.

Interpretation: Delignification of jute by using lignin degrading bacteria without any environmental hazard may be considered as an alternate method of chemical delignification for minimization of environmental pollution.

Key words: Delignification, High lignin, Jute, Ligninolytic bacterial isolates, Textile industry

\section{Abstract}

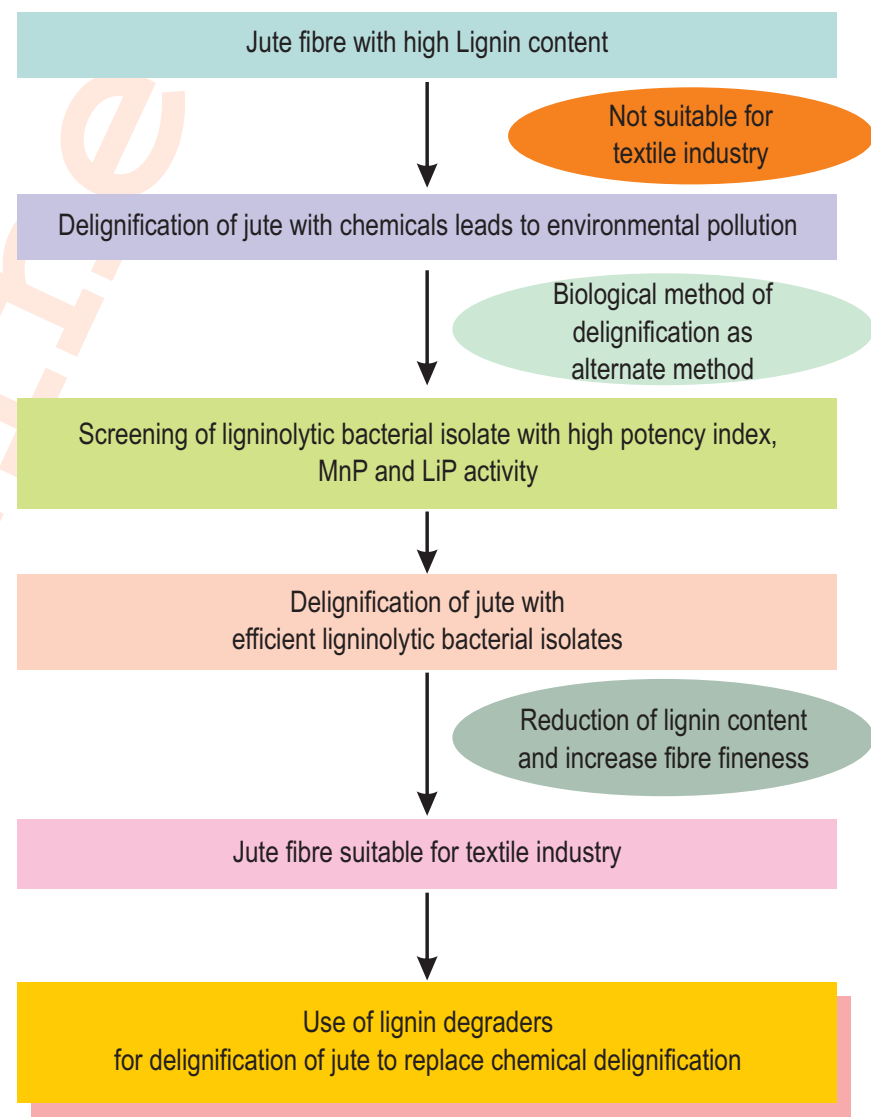

How to cite : Barai, S., L. Chattopadhyay and B. Majumdar: Studies on delignification in jute (Corchorus spp L.) fibre with promising lignin degrading bacterial isolates. J. Environ. Biol., 41, 703-710 (2020). 


\section{Introduction}

Jute (Corchorus capsularis L. and C. olitorius L.) is a very important cash crop of eastern India, cultivated for fully biodegradable lignocellulosic bast fibres used for diversified jute products, geotextiles and paper pulp and to some extent in textile industries. Jute lignin is a complex polyphenolic polymer composed of $p$-hydroxyphenyl $(H)$, guaiacyl $(G)$ and syringyl $(S)$ units in 2:32:66 ratio with a S/G ratio of 2.1 (Del Rio et al., 2009). The lignin content in jute fibre varies from 13.3 to $15 \%$ (Del Rio et al., 2009; Chakraborty et al., 2015; Sengupta and Palit, 2004), which is high as compared to other important bast fibres like flax and ramie having less than $5 \%$ lignin (Sengupta and Palit, 2004) and is extensively used in textile industry. Higher lignin content in jute fibre is restricting its use as a textile fibre. Lignin content in jute fibre has inverse relationship with fibre fineness (Meshram and Palit, 2013) and photo yellowing of jute products also occurs because of reaction of a-carboxyl group of lignin with UVradiation (Chakraborty et al., 2015) making jute fibre unsuitable for fine quality fabrics and apparel production.

So, there is an urgent need for low-lignin containing jute fibre in jute based industries to enable them to produce high quality textile products. There are two possible ways for getting low lignin jute fibre. Development of low lignin jute variety by specialized breeding and genetic engineering techniques is one of the ways to get low lignin jute fibre, and the second way is delignification of jute fibre either by chemical or enzymatic action using lignin degrading microbes.

Bleaching of wood pulp to remove lignin, xylan by the paper industry, discharge of large amount of toxic chlorinated and aromatic compounds in the environment are the major source of environmental pollution (Shoham et al., 1992). Use of laccase and mediator system (LMS) for delignification of jute lignin showed that the molecular weight of lignin from LMS treated jute fibre was lower than the lignin from the control jute fibre which could guide the enzymatic process of ligno-cellulose materials in textile and allied sector (Zhang et al., 2014). Jute fibre is chemically modified for various diversified textile use, where jute lignin is either modified or partially degraded by hydrolysis with sulphuric acid leading to sulphonated lignin in the waste solution creating environmental hazard (Hussain et al., 2002). In the traditional process, the lignin in jute fibre is eliminated mainly by degumming using some chemicals, which often causes severe environmental pollution (Kumar et al., 2014; Kamali and Khodaparasat, 2015). In order to overcome the disadvantages of chemical degumming, biological method of delignification may serve as an alternative option with very few limitations (Huang et al., 2013). It involves the use of microorganisms or immobilized microbial sub molecules such as enzymes, which is cheap and environmental friendly.

Fungal enzymes have limited industrial utility in relation to its protein expression, genetic manipulations and lack of stability under high $\mathrm{pH}$, oxygen limitation and higher lignin concentrations (Crawford and Muralidhara. 2004)., whereas bacterial enzymes are relatively easy to produce. The studies on lignin degradation by using bacterial isolates and increase in production of ligninolytic enzymes of bacterial origin for delignification have been observed in recent years (Renugadevi et al., 2011). A pectinolytic bacterial consortium capable of secreting pectinase and xylanase enzymes was used as talc based microbial formulation (Das et al., 2015; Das et al., 2018) and as endospores (Chattopadhyay et al., 2019) for jute retting was found to improve jute fibre quality but impact on delignification was not studied. Further, xylanase production by immobilized cells of Bacillus pumilus was 40.5 and $132.6 \%$ higher over its free cells respectively after 48 and $72 \mathrm{hr}$ of the incubation (Kundu and Majumdar, 2018). The ability to degrade lignin by bacteria is more advantageous compared to fungi such as the ability to adapt better in anaerobic conditions (Huang et al., 2013) and higher potential due to its environmental adaptability and biochemical versatility (Abd-Elsalam and El-Hanafy, 2009).

Ligninolytic heme-peroxidases including manganese peroxidase $(\mathrm{MnP})$, lignin peroxidase $(\mathrm{LiP})$ and versatile peroxidase (VP) of either fungal or bacterial origin play central role in delignification (Ruiz-Duenas and Martinez, 2009). The $\mathrm{MnP}$ and LiP oxidizes respectively the phenolic and non-phenolic component of lignin (Falade et al., 2016). Besides the oxidation of non-phenolic substrates, guaiacol, acetosyringone, catechol, vanillyl alcohol and syringic acid like phenolics are susceptible to the oxidative potential of LiP (Wong, 2009).

With the advantages of immense environmental adaptability and biochemical versatility, bacteria deserve to be studied for their ligninolytic potential. Therefore, this study aimed to screen, isolate and identify novel bacteria producing lignin degrading enzymes that have potential for delignification of lignocellulosic biomass of jute.

\section{Materials and Methods}

Collection of water samples and isolation of ligninolytic bacterial strains: The jute retting water samples were collected from various jute growing districts of West Bengal. Decayed material of fallen trees and soil samples were collected from the ICAR-CRIJAF campus and sawmills of North 24 parganas district. Enumerations of lignin degrading bacterial strains from the above collected samples were done on lignin agar media (lignin sulfonic acid $\mathrm{Na}$ salt- $1 \%$; $\mathrm{NaCl}-0.5 \% ; \mathrm{MgSO}_{4}-0.02 \%$; peptone-0.5\%; $\mathrm{KH}_{2} \mathrm{PO}_{4}-0.05 \%$; and agar- $1.8 \%$ at $\left.\mathrm{pH}-7.5\right)$ following serial dilution technique and pour plate method (Parmer and Schmidt, 1966). The plates were then incubated at $37^{\circ} \mathrm{C}$ for $48 \mathrm{hr}$. The efficient ligninolytic isolates were selected and were separately streaked on fresh lignin-agar plates to obtain single bacterial colonies. 
Screening of efficient ligninolytic bacterial isolates: Ligninolytic isolates were then grown on LBM medium (lignin modifying enzyme basal medium) composed of $\left(\mathrm{KH}_{2} \mathrm{PO}_{4}-1 \mathrm{gl}^{-1}\right.$; $\mathrm{C}_{4} \mathrm{H}_{12} \mathrm{~N}_{2} \mathrm{O}_{6}-0.5 \mathrm{gll}^{-1} ; \mathrm{MgSO} 4.7 \mathrm{H}_{2} \mathrm{O}-0.5 \mathrm{gl}^{-1} ; \mathrm{CaCl}_{2} 2 \mathrm{H}_{2} \mathrm{O}-0.01 \mathrm{gl}^{-1} ;$ yeast extract- $0.01 \mathrm{gl}^{-1} ; \mathrm{CuSO}_{4} 5 \mathrm{H}_{2} \mathrm{O}-0.001 \mathrm{gl}^{-1} ; \mathrm{Fe}\left(\mathrm{SO}_{4}\right)_{3}-0.001$ $\mathrm{gl}^{-1} ; \mathrm{MnSO}_{4} \mathrm{H}_{2} \mathrm{O}-0.001 \mathrm{~g} \mathrm{l}^{-1} ; 20 \%$ glucose solution- $10 \mathrm{ml} \mathrm{l}^{-1}$ and $1.6 \%$ agar powder) containing $0.01 \%$ Azure-B to check their azo dyes degradation ability. Glucose solution was separately autoclaved and mixed with the medium just before plating. Inoculation was done by spot plate method, following the qualitative method of Pointing (1999). A clear hydrolysed zone around the colonies indicates the lignin degrading ability of the bacterial strains. The potency index of each isolate was calculated as the ratio of zone diameter to the colony diameter. The isolates showing higher potency index $(\geq 1.10)$ were selected for further screening on the basis of their laccase activity. These bacterial isolates were again plated on LBM agar plates supplemented with $0.1 \%$ ABTS (2, 2'-azino-bis (3ethylbenzothiazoline-6-sulphonic acid) to check their production capacity of extracellular laccase. The colourless ABTS agar medium turns green due to oxidation of ABTS to ABTS-azine in the presence of laccase, which is considered as a positive test for laccase activity (Niku-Paavola et al., 1990).

Enzyme activity assays: Bacterial isolates screened on the basis of their dye degrading ability were selected for enzyme assay. All the isolates were freshly inoculated in $10 \mathrm{ml}$ of $0.5 \%$ lignin broth and grown for $18 \mathrm{hr}$ at $130 \mathrm{rpm}$ at $34^{\circ} \mathrm{C}$. The starter cultures were then used as inoculum ( $5 \% \mathrm{~V} / \mathrm{v}$ ) into $25 \mathrm{ml}$ of $0.5 \%$ lignin broth and incubated at $34^{\circ} \mathrm{C}$ with shaking at $130 \mathrm{rpm}$ for 6 days. Aliquots were collected for $24-144 \mathrm{hr}$. After centrifugation of cultures at 10,000 rpm for $5 \mathrm{~min}$, supernatants were used as the sole source of enzyme for lignin peroxidase (LiP) and manganese peroxidase (MnP) assays (Magalhaes et al., 1996; Pease et al., 1991).

Lignin peroxidase activity: Lignin peroxidase activity was determined based on demethylation of methylene blue dye, where methylene blue acts as a substrate and enzyme LiP demethylates in the presence of $\mathrm{H}_{2} \mathrm{O}_{2}$ (inducer). The reaction mixture contains $0.1 \mathrm{ml}$ of $0.1 \mathrm{mM} \mathrm{H}_{2} \mathrm{O}_{2}, 32 \mu \mathrm{M}$ methylene blue as substrate, $10 \mu$ l of culture supernatant as enzyme and $1 \mathrm{ml}$ of 50 $\mathrm{mM}$ sodium potassium tartrate $(\mathrm{pH}-4)$ buffer. The solution was incubated at room temperature for $1 \mathrm{hr}$. The absorbance was measured at $650 \mathrm{~nm}$ using an UV-visible spectrophotometer (Mecasys, Optizen). A test control (without culture supernatant) was run simultaneously. The amount of decolourization of methylene blue dye was calculated as decrease in absorbance at $650 \mathrm{~nm}^{-1} \mathrm{~min}^{-1}$.

Manganese peroxidase activity: A reaction mixture containing $25 \mathrm{mM}$ lactate; $0.1 \mathrm{mM} \mathrm{MnSO}_{4 ;} 1 \mathrm{mg} \mathrm{ml}^{-1}$ bovine serum albumin (BSA); and $0.1 \mathrm{mg} \mathrm{ml}^{-1}$ of phenol red in $20 \mathrm{mM}$ sodium succinate (pH 4.5) buffer in a total volume of $1 \mathrm{ml}$ in which $0.5 \mathrm{ml}$ culture supernatant was added. The reaction was initiated by adding 0.1 $\mathrm{ml}$ of $0.1 \mathrm{mM} \mathrm{H}_{2} \mathrm{O}_{2}$ at $30^{\circ} \mathrm{C}$ and was stopped after 1 min with $50 \mu \mathrm{l}$ of $10 \% \mathrm{NaOH}$ and the absorbance was measured with an UVvisible spectrophotometer (Mecasys, Optizen) at $610 \mathrm{~nm}$. The control assays of phenol red oxidation in the absence of $\mathrm{Mn}^{2+}$ were carried out by omitting $\mathrm{MnSO}_{4}$ from the reaction mixture for every isolate. The MnP activity was calculated and expressed as increase in absorbance at $610 \mathrm{nml}^{-1} \mathrm{~min}^{-1}$.

Delignification trial with selected lignifying bacterial isolates: The bacterial strains selected on the basis of their potency index and enzyme producing ability ( $L i P$ and $M n P)$, were used in a laboratory scale delignification trial with retted jute fibre to check delignification ability. These isolates were freshly inoculated in $100 \mathrm{ml}$ of $0.5 \%$ lignin broth and grown for $18 \mathrm{hr}$ separately. In each $2 \mathrm{I}$ round bottom flasks, approximately $200 \mathrm{~g}$ of retted jute fibre was immersed in 11 of minimal media (peptone 5 $\mathrm{gl}^{-1} ;$ glucose $10 \mathrm{gl}^{-1} ; \mathrm{KH}_{2} \mathrm{PO}_{4} 2 \mathrm{gl}^{-1} ; \mathrm{MgSO}_{4} 1 \mathrm{gl}^{-1} ;$ and $\mathrm{NaCl} 1 \mathrm{gl}{ }^{-1}$ at $\mathrm{pH}-7.5)$ and autoclaved. The flasks were then inoculated with the broth culture of selected bacterial strains ( $5 \% \mathrm{v} / \mathrm{v})$ separately and incubated at $34^{\circ} \mathrm{C}$ for seven days. After incubation, fibre samples were washed and used for lignin and fibre quality estimation.

Estimation of lignin in jute fibre samples: Lignin content of retted fibres was estimated as acid detergent lignin (ADL) using FibreCap ${ }^{\mathrm{TM}} 2021$ of the Fibertec ${ }^{\mathrm{TM}} 2021$ system (FOSS Analytical A/S, Hilleroed, Denmark) as described by Kundu et al. (2012). Lignin content was estimated in jute fibre samples used for delignification study before and after delignification trial. A control was also run for each of the three replicates with untreated jute fibre to compare the amount of lignin reduction in treated ones.

Fibre quality analysis: Tensile strength of treated and untreated fibre samples was measured by the method of Roy et al. (2009) using an electronic fibre bundle strength tester and fibre fineness of samples were estimated by using the airflow method of Bandyopadhyay and Sinha (1968).

Identification of bacterial strains: The efficient ligninolytic bacterial strains were identified up to species level by using the Biolog Inc. (Hayward, U.S.A), an advanced tool for characterization and identification of microorganisms based on the metabolic fingerprinting pattern of the isolates using the software ML_51_01_ml3. Freshly grown microbial colonies were suspended in inoculating fluid and cell density was adjusted as per recommendation. A $100 \mu$ bacterial suspension was then inoculated into GEN III micro plates of Biolog and incubated up to $22 \mathrm{hr}$ at $33^{\circ} \mathrm{C}$. The micro plates were read after 8,16 and $22 \mathrm{hr}$ of incubation by using the Biolog Inc, for identification.

Statistical analysis: The data were analysed for standard deviation by using Microsoft excel 2010 version. 


\section{Results and Discussion}

The jute retting water samples, decayed plant materials and soil samples were used to isolate the ligninolytic bacterial isolates on lignin agar media. Ninety-five ligninolytic bacterial isolates were isolated initially from the collected samples. After that, the pure strains of these isolates were used to check for their lignocellulolytic enzyme activity through qualitative methods i.e. dye-degradation ability. Decolourization of dye Azure-B has been positively correlated with production of lignin peroxidase and $\mathrm{Mn}$ dependent peroxidase. Among the isolated strains, some isolates could degrade Azure-B dye by creating colourless or halo (hydrolized) zone around the bacterial growth on the Azure B agar plate (blue in colour). The area of dye decolourization was then recorded. None of the 95 isolates showed any green spot on colourless ABTS agar plate, thus indicating negative result which signifies no laccase production. On the basis of Azure B dye degradation test, twenty bacterial isolates showing potency index $\geq 1.10$ were selected for enzymatic assay. Among these twenty isolates, four isolates had potency index more than 2 (Fig.1). The ligninolytic isolates $L 3, L 9, L 26$ and $L 30$ had potency index of $2.60,2.49,2.42$ and 2.58 respectively. The potency indexes of these four isolates (L3, L9, L26 and L30) were much higher compared with the remaining ligninolytic isolates selected for enzyme assay. Screening of bacterial isolates on the basis of potency index for pectinolytic activities has also been reported by Das etal. (2015).

Twenty Azure B positive strains having higher potency index were then used for enzymatic assay. These isolates were grown in lignin broth media and the presence of manganese dependent peroxidase and lignin peroxidase enzyme was checked spectrophotometrically, starting from $24^{\text {th }} \mathrm{hr}$ of incubation till $144^{\text {th }} \mathrm{hr}$. The enzyme production assay was carried out in triplicate and the mean value was taken for further interpretation.

The data presented in Table 1 indicates the manganese peroxidase activity by twenty ligninolytic isolates under study in different time intervals ranging from 24 to $144 \mathrm{hr}$ of incubation. After $24 \mathrm{hr}$ of incubation, only four isolates (L3, L10, L23 and L26) showed very low activities ( 1 to $3 \mathrm{UI}^{-1} \mathrm{~min}^{-1}$ ), but the remaining 16 isolates did not show any activity. All the isolates, except isolate no $L 75$, showed manganese peroxidase activity after $48 \mathrm{hr}$ of incubation, but isolate L75 did not show any activity even after $144 \mathrm{hr}$ of incubation. The Mn peroxidase activities of isolates L3, L9, L10, L13, L15, L23, L26, L30 and L42 were increased with increase in incubation time up to $96 \mathrm{hr}$ and thereafter the activities reduced. After $96 \mathrm{hr}$ of incubation, the highest Mn peroxidase was recorded by the isolate $\mathrm{L} 10\left(482 \mathrm{Ul}^{-1} \mathrm{~min}^{-1}\right)$ followed by L26 (294 U $\left.\mathrm{I}^{-1} \mathrm{~min}^{-1}\right), \mathrm{L} 9\left(275 \mathrm{Ul}^{-1} \mathrm{~min}^{-1}\right), \mathrm{L} 3\left(147 \mathrm{Ul}^{-1} \mathrm{~min}^{-1}\right)$ and L30 (126 Ul $\mathrm{I}^{-1}$ $\left.\mathrm{min}^{-1}\right)$. Interestingly, the isolate L44 showed increasing $\mathrm{Mn}$ peroxidase activity up to $120 \mathrm{hr}$ of incubation $\left(102 \mathrm{Ul}^{-1} \mathrm{~min}^{-1}\right)$ and then maintained the same activity even after $144 \mathrm{hr}$ of incubation.
The remaining ligninolytic isolates ( $L 47, \mathrm{~L} 53, \mathrm{~L} 62, \mathrm{~L} 67, \mathrm{~L} 71$, L74, L75, L82, L87 and L89) did not show any definite trend of increase in activity and they did not show any activity after 120 and $144 \mathrm{hr}$ of incubation. From the Mn peroxidase activity data, it was visible that the isolates $L 3, L 9, L 10, L 26$ and $L 30$ recorded higher enzymatic activity besides recording higher potency index among the isolates under study. These promising ligninolytic isolates ( L3, $\mathrm{L} 9, \mathrm{~L} 10, \mathrm{~L} 26$ and L30) with higher MnP activity were identified as Bacillus spp. In earlier studies, Bacillus spp with higher delignification activity were also reported by Huang et al. (2013) and Woo et al. (2014).

The lignin peroxidase activity of isolates $L 3, L 9, L 10, L 13$, L15, L23, L26, L30, L44, L62, L67 and L71 increased with time of incubation up to $96 \mathrm{hr}$, thereafter the enzyme activity of these isolates reduced at 120 and $144 \mathrm{hr}$ of incubation (Table 2). Among these isolates, the highest lignin peroxidase activity of $615.6 \mathrm{Ul}^{-1}$ $\mathrm{min}^{-1}$ after $96 \mathrm{hr}$ of incubation was recorded by the isolate L9 followed by L3 (571.2 $\left.\mathrm{Ul}^{-1} \mathrm{~min}^{-1}\right)$, L26 (566.2 $\left.\mathrm{Ul}^{-1} \mathrm{~min}^{-1}\right)$, L30 (560.7 $\left.\mathrm{Ul}^{-1} \mathrm{~min}^{-1}\right)$ and $\mathrm{L} 10\left(558.7 \mathrm{Ul}^{-1} \mathrm{~min}^{-1}\right)$. The lignin peroxidase activity of the isolate L9 after $96 \mathrm{hr}$ of incubation was higher by 7.8 to $24.8 \%$ over all the isolates under study. The remaining ligninolytic isolates (L42, L47, L53, L74, L75, L82, L87 and L89) showed increase in lignin peroxidase activity up to $72 \mathrm{hr}$ of incubation, thereafter the enzyme activity reduced with increase in incubation time up to $144 \mathrm{hr}$. Among these isolates, the highest lignin peroxidase activity after $72 \mathrm{hr}$ of incubation was recorded by the isolate L75 (557.5 $\left.\mathrm{Ul}^{-1} \mathrm{~min}^{-1}\right)$ followed by L74 (552.0 $\left.\mathrm{Ul}^{-1} \mathrm{~min}^{-1}\right)$ and $\mathrm{L} 42\left(551.7 \mathrm{UI}^{-1} \mathrm{~min}^{-1}\right)$. Five isolates viz. L3, L9, L10, L26 and L30 recorded higher lignin peroxidase activity after $96 \mathrm{hr}$ of incubation, which also recorded higher manganese peroxidase activity and potency index among the 20 isolates under study. Jute lignin is a complex polyphenolic polymer which has major components like guaiacyl and syringyl. Phenolics like guaiacyl and syringyl are highly susceptible to oxidative potential of LiP (Wong, 2000), hence the isolates L3, L9, L10, L26 and $L 30$ having higher LiP could play a crucial role in delignification of jute fibre. Further, these five promising isolates were identified as Bacillus spp. This is in agreement with the findings of Huang et al. (2013) and Woo et al. (2014), who had reported Bacillus spp. with higher delignification capacity.

On the basis of potency index and enzymatic activity ( $\mathrm{MnP}$ and LiP), five promising ligninolytic bacterial isolates ( $\mathrm{L} 3$, $L 9, L 10, L 26$ and L30) were used for delignification study of jute fibre. After delignification study, the resultant jute fibre samples were processed and analysed for lignin content (Fig. 2). The lignin content data indicates that all the five ligninolytic isolates used for delignification study were found to decrease the lignin content in jute fibre compared with the control. This could be due to higher LiP and MnP activities of these five bacterial isolates, which are primarily responsible to carry out the delignification process (Ruiz-Duenas and Martinez, 2009). The delignification 
Table 1: Changes in manganese peroxidase activity of ligninolytic isolates at different time intervals

\begin{tabular}{|c|c|c|c|c|c|c|}
\hline \multirow{2}{*}{$\begin{array}{l}\text { Ligninolytic } \\
\text { isolates }\end{array}$} & \multicolumn{6}{|c|}{ Manganese peroxidase activity $\left(\mathrm{Ul}^{-1} \mathrm{~min}^{-1}\right)$} \\
\hline & $24 \mathrm{hr}$ & $48 \mathrm{hr}$ & $72 \mathrm{hr}$ & $96 \mathrm{hr}$ & $120 \mathrm{hr}$ & $144 \mathrm{hr}$ \\
\hline L3 & $2 \pm 0.5$ & $7 \pm 2$ & $276 \pm 16$ & $147 \pm 32$ & $90 \pm 2$ & $69 \pm 5$ \\
\hline L9 & 0 & $5 \pm 1$ & $125 \pm 13$ & $275 \pm 9$ & $254 \pm 14$ & $57 \pm 5.9$ \\
\hline L10 & $3 \pm 0.8$ & $90 \pm 0.8$ & $13 \pm 3.4$ & $482 \pm 14.4$ & $10 \pm 8$ & 0 \\
\hline L13 & 0 & $3 \pm 1$ & $9 \pm 4$ & $77 \pm 4$ & $13 \pm 2$ & $2 \pm 0.1$ \\
\hline L15 & 0 & $3 \pm 1$ & $10 \pm 2$ & $33 \pm 11$ & $30 \pm 3$ & $25 \pm 1.4$ \\
\hline L23 & $1 \pm 0.9$ & $5 \pm 0.8$ & $9 \pm 0.16$ & $106 \pm 17.4$ & $18 \pm 2.5$ & $5 \pm 0.4$ \\
\hline L26 & $1 \pm 0.5$ & $8 \pm 0.5$ & $90 \pm 13.9$ & $294 \pm 17.6$ & $108 \pm 11.8$ & $97 \pm 17.2$ \\
\hline L30 & 0 & $6 \pm 1$ & $82 \pm 11$ & $143 \pm 37$ & $126 \pm 0.011$ & $113 \pm 6$ \\
\hline L42 & 0 & $4 \pm 0.8$ & $6 \pm 1.2$ & $7 \pm 0.8$ & $6 \pm 1.2$ & $5 \pm 1.2$ \\
\hline L44 & 0 & $3 \pm 0.9$ & $90 \pm 4.9$ & $94 \pm 6.7$ & $102 \pm 12$ & $102 \pm 6.9$ \\
\hline L47 & 0 & $2.3 \pm 0.5$ & $13 \pm 1.2$ & $1 \pm 1.2$ & 0 & 0 \\
\hline L53 & 0 & $2 \pm 0.5$ & $7 \pm 0.9$ & $2 \pm 0.5$ & 0 & 0 \\
\hline L62 & 0 & $4 \pm 0.8$ & $7 \pm 0.8$ & 0 & 0 & 0 \\
\hline L67 & 0 & $5 \pm 0.1$ & $8 \pm 0.9$ & 0 & 0 & 0 \\
\hline L71 & 0 & $0.3 \pm 0.5$ & $1.7 \pm 0.5$ & 0 & 0 & 0 \\
\hline L74 & 0 & $2 \pm 0.5$ & $4 \pm 0.5$ & $1 \pm 0.8$ & 0 & 0 \\
\hline L75 & 0 & 0 & 0 & 0 & 0 & 0 \\
\hline L82 & 0 & $2 \pm 0.8$ & $5 \pm 1.2$ & 0 & 0 & 0 \\
\hline L87 & 0 & $4 \pm 0.8$ & $7 \pm 1.2$ & $1 \pm 0.9$ & 0 & 0 \\
\hline L89 & 0 & $1 \pm 0.8$ & $3 \pm 0.5$ & $6 \pm 0.8$ & 0 & 0 \\
\hline
\end{tabular}

Values (mean \pm S.D.) in each row for a particular set

Table 2: Changes in lignin peroxidase activity of ligninolytic isolates at different time intervals

\begin{tabular}{|c|c|c|c|c|c|c|}
\hline \multirow{2}{*}{$\begin{array}{l}\text { Ligninolytic } \\
\text { isolates }\end{array}$} & \multicolumn{6}{|c|}{ Lignin peroxidase activity $\left(\mathrm{Ul}^{-1} \mathrm{~min}^{-1}\right)$} \\
\hline & $24 \mathrm{hr}$ & $48 \mathrm{hr}$ & $72 \mathrm{hr}$ & $96 \mathrm{hr}$ & $120 \mathrm{hr}$ & $144 \mathrm{hr}$ \\
\hline L3 & $485.5 \pm 6.5$ & $507.2 \pm 6.3$ & $539.8 \pm 2.0$ & $571.2 \pm 2.2$ & $516.2 \pm 5.9$ & $504.4 \pm 7.5$ \\
\hline L9 & $498.9 \pm 8.9$ & $522.3 \pm 3.5$ & $561.6 \pm 6.6$ & $615.6 \pm 2.6$ & $525.7 \pm 8.8$ & $522.9 \pm 6.2$ \\
\hline L10 & $500.3 \pm 9.1$ & $511.8 \pm 12.8$ & $527.8 \pm 6.8$ & $558.7 \pm 2.1$ & $534.7 \pm 2.3$ & $522.9 \pm 2.6$ \\
\hline L13 & $481.6 \pm 5.3$ & $495.5 \pm 7.0$ & $513.5 \pm 1.2$ & $516.6 \pm 3.8$ & $498.6 \pm 2.8$ & $491.2 \pm 4.8$ \\
\hline L15 & $490.4 \pm 7.3$ & $493.7 \pm 2.9$ & $527.6 \pm 4.5$ & $539.3 \pm 1.9$ & $526.0 \pm 4.0$ & $511.9 \pm 3.0$ \\
\hline L23 & $481.2 \pm 3.9$ & $500.5 \pm 4.3$ & $508.9 \pm 5.3$ & $521.8 \pm 1.6$ & $513.4 \pm 5.1$ & $502.8 \pm 3.2$ \\
\hline L26 & $478.9 \pm 12.2$ & $492.6 \pm 9.5$ & $506.1 \pm 7.5$ & $566.2 \pm 5.5$ & $533.9 \pm 7.3$ & $494.2 \pm 5.6$ \\
\hline L30 & $490.9 \pm 8.4$ & $499.8 \pm 4.6$ & $506.4 \pm 7.8$ & $560.7 \pm 2.9$ & $535.4 \pm 10.0$ & $509.5 \pm 8.1$ \\
\hline L42 & $492.5 \pm 10.4$ & $539.1 \pm 10.6$ & $551.7 \pm 10.2$ & $512.3 \pm 11.2$ & $504.8 \pm 9.8$ & $483.0 \pm 11.2$ \\
\hline L44 & $495.2 \pm 13.1$ & $501.7 \pm 11.4$ & $515.9 \pm 10.4$ & $525.4 \pm 10.8$ & $509.1 \pm 9.2$ & $504.9 \pm 8.4$ \\
\hline L47 & $484.4 \pm 7.7$ & $520.7 \pm 8.1$ & $547.9 \pm 11.3$ & $519.3 \pm 11.7$ & $510.8 \pm 8.0$ & $498.2 \pm 9.0$ \\
\hline L53 & $487.6 \pm 13.3$ & $503.7 \pm 9.0$ & $526.7 \pm 12.4$ & $493.2 \pm 9.9$ & $487.5 \pm 7.6$ & $476.2 \pm 10.5$ \\
\hline L62 & $496.0 \pm 9.2$ & $502.1 \pm 9.6$ & $521.7 \pm 8.4$ & $549.0 \pm 9.2$ & $523.0 \pm 10.8$ & $500.7 \pm 15.0$ \\
\hline L67 & $482.3 \pm 8.3$ & $509.6 \pm 9.7$ & $522.0 \pm 7.1$ & $529.8 \pm 8.2$ & $517.6 \pm 8.0$ & $491.9 \pm 10.4$ \\
\hline L71 & $510.0 \pm 12.5$ & $515.3 \pm 7.4$ & $521.9 \pm 10.3$ & $545.3 \pm 18.0$ & $526.4 \pm 9.4$ & $514.4 \pm 10.6$ \\
\hline L74 & $489.5 \pm 10.5$ & $513.4 \pm 12.4$ & $552.0 \pm 10.5$ & $508.4 \pm 12.6$ & $507.8 \pm 14.0$ & $497.0 \pm 12.7$ \\
\hline L75 & $493.7 \pm 8.7$ & $543.2 \pm 10.7$ & $557.5 \pm 5.8$ & $542.1 \pm 7.3$ & $529.5 \pm 6.2$ & $508.4 \pm 8.9$ \\
\hline L82 & $493.1 \pm 14.1$ & $512.9 \pm 11.1$ & $545.7 \pm 11.1$ & $528.3 \pm 11.4$ & $512.1 \pm 13.8$ & $503.0 \pm 15.9$ \\
\hline L87 & $479.9 \pm 5.5$ & $512.8 \pm 9.9$ & $545.1 \pm 10.5$ & $525.4 \pm 10.0$ & $521.3 \pm 6.8$ & $503.2 \pm 11.6$ \\
\hline L89 & $481.4 \pm 8.5$ & $515.0 \pm 7.71$ & $548.0 \pm 11.7$ & $529.7 \pm 11.1$ & $503.6 \pm 9.3$ & $507.4 \pm 9.8$ \\
\hline
\end{tabular}

Values (mean \pm S.D.) in each row for a particular set 


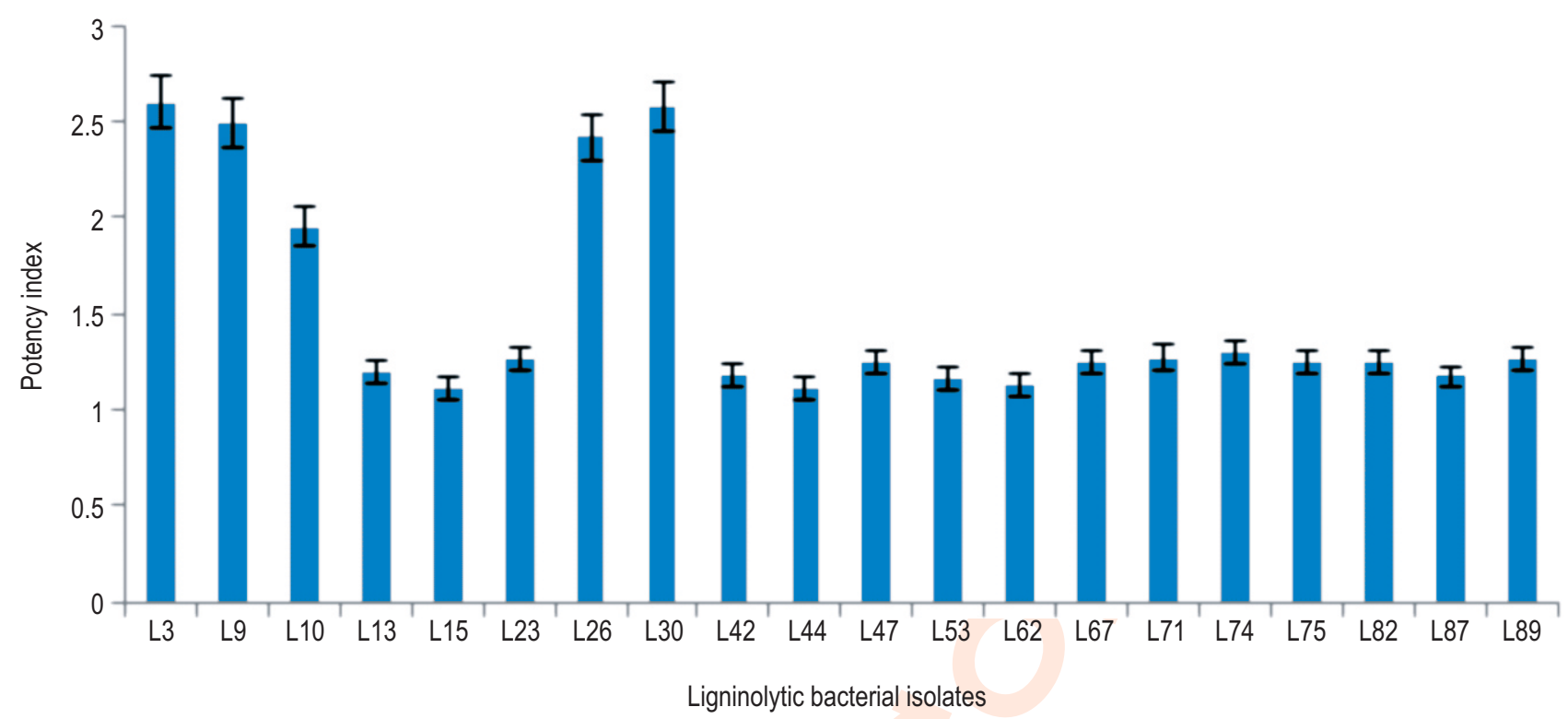

Fig. 1 : Potency Index of different ligninolytic isolates in Azure-B dye test.

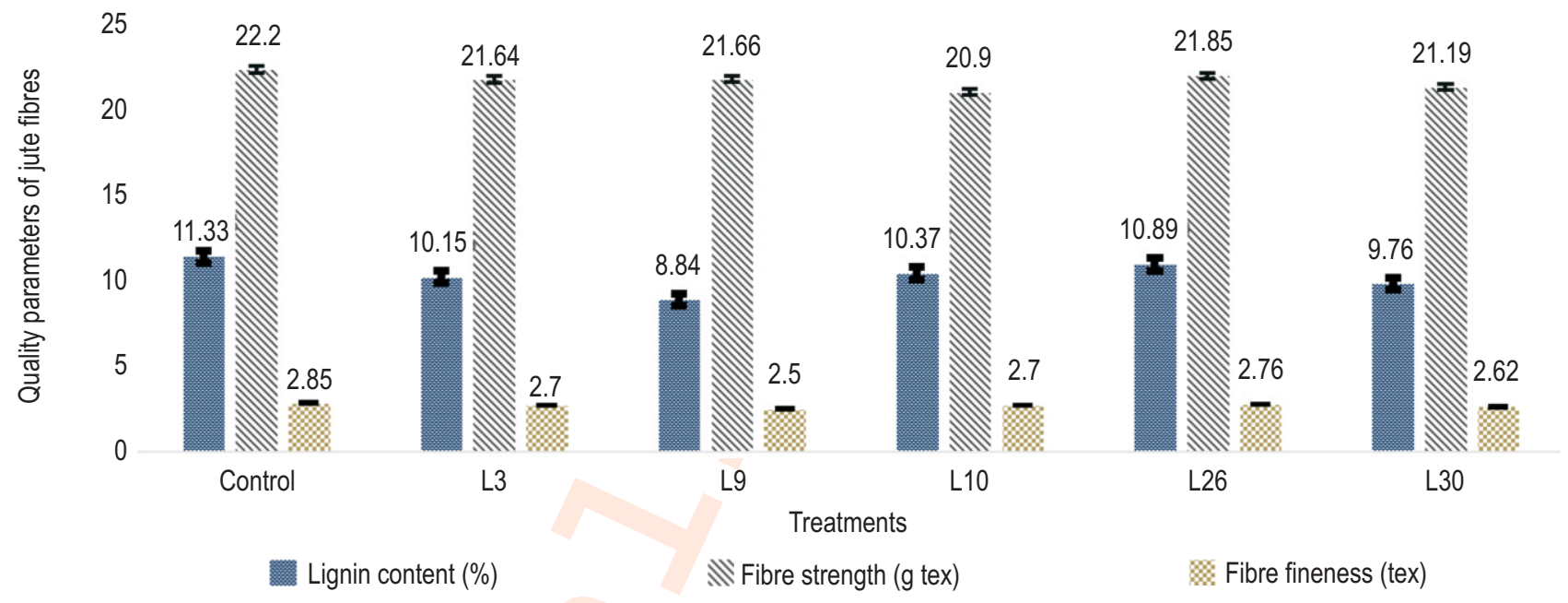

Fig. 2 : Effect of delignification with promising ligninolytic isolates on jute fibre quality.

trial of jute fibre was carried out at slightly alkaline $\mathrm{pH}$ (7.5) which might have helped in higher delignification as high S-lignin content in jute fibre is advantageous for delignification due to higher reactivity of S-lignin in alkaline system (Chang and Sarkanen, 1973; Tsutsumi et al., 1995). Among the five isolates, isolate $\mathrm{L} 9$ was the best performer in delignifying the jute fibre, which had reduced the lignin content from 11.33 to $8.84 \%$, i.e. a reduction of $21.97 \%$ from the control. The isolate L3 also performed very well, which had reduced the lignin content in jute fibre from 11.33 to $9.76 \%$, i.e. a reduction of $13.8 \%$ from the control followed by the isolates $L 3, L 10$ and $L 26$. The isolate $L 9$ was later identified as Bacillus subtilis. The higher delignification capacity of $\mathrm{L} 9$ might be due to high $\mathrm{LiP}\left(615.6 \mathrm{UI}^{-1} \mathrm{~min}^{-1}\right)$ and $\mathrm{MnP}$ (275 $\mathrm{U} \mathrm{I}^{-1} \mathrm{~min}^{-1}$ ) activity which helped in the degradation of phenols like guaiacyl and syringyl present in jute lignin as these phenols are sensitive for degradation to the oxidative potential of LiP (Wong, 2009). Further, the combined action of MnP and LiP helped in oxidation of the phenolic and non-phenolic component of jute lignin respectively (Falade et al., 2016) resulting higher delignification of jute fibre. Hence, a reduction of $21.97 \%$ in lignin content of jute fibre was observed where fibre was treated for delignification with highly active ligninolytic isolate L9. 
The fibre strength data presented in the Fig. 2 revealed that after delignification trial with five promising ligninolytic isolates, the fibre strength reduced marginally with all the isolates compared with the control. Among the isolates, the highest fibre strength ( $\left.21.85 \mathrm{~g} \mathrm{tex}^{-1}\right)$ was recorded with the isolate L9 followed by the isolate L30 (21.66 g tex $\left.{ }^{-1}\right)$ and L3 (21.64 g tex $\left.{ }^{-1}\right)$ which were lower than the fibre strength $\left(22.20 \mathrm{~g}^{-1} \mathrm{x}^{-1}\right)$ recorded in control. The fibre strength recorded in control was higher by only $1.6 \%$ over the best isolate L9.

Interestingly, the fibre fineness increased (decrease tex value) with all the five ligninolytic isolates under study compared with the control (Fig. 2). The maximum increase in fibre fineness ( 2.50 tex) was recorded with the isolate $L 9$ followed by isolate $L 30$ (2.62 tex) compared with the control (2.85 tex). The lower fibre fineness value (tex value) indicates that the fibre fineness is higher; hence, the higher fibre fineness was recorded with all the ligninolytic isolates compared with the control after delignification study. Higher lignin value in jute fibre reduces the quality and commercial value of the fibre because of higher rigidity and roughness (Sharma, 1986), hence the reduction in lignin value in jute fibre with the ligninolytic bacterial isolates might have increased the fibre quality and spinnability of the fibre as indicated by higher fineness of the resultant fibre (Fig. 2). This higher fibre fineness recorded with all the five ligninolytic isolates correspond to decrease in lignin content in fibre because of delignification. Lowering the lignin content in jute fibre in the present study helped in increase in fibre fineness of jute fibre which is supported by the findings of Meshram and Palit (2013), where they have shown an inverse relationship between lignin content and fibre fineness in jute fibre. The reduction in lignin content of jute fibre by using ligninolytic bacterial isolates helped in increase in fibre fineness and the resultant fibre can also be utilized for textile purposes, due to higher spinnability with increase in fibre fineness (Grishanov etal., 2006).

The five promising ligninolytic bacterial strains used for delignification study were identified up to the species level by BIOLOG microbial identification system after 8,16 and $22 \mathrm{hr}$ of incubation. The isolates $L 3$ and $L 9$ were identified as two different strains of Bacillus subtilis, whereas the isolate $L 10$ and $L 26$ were identified as two different strains of Bacillus amyloliquefaciens and the isolate L30 was identified as Bacillus licheniformis. The bacterial isolates like Bacillus subtilis, Bacillus licheniformis and Bacillus circulans were also isolated and reported to help in biodegradation of lignin in compost environment (Tuomela et al., 2000 ) and $87 \%$ of the bacterial genera belonged to Bacillus spp. during thermophilic phase of composting (Strom, 1985). Hence the ligninolytic bacterial isolates of the present study can play an important role in delignification of jute fibre in near future.

It can be concluded from the present study that, by using efficient lignin degrading bacterial isolates delignification of jute fibre is possible to a great extent making the jute fibre suitable for textile purposes. Further, the environmental pollution from chemical process of delignification can be overcome by using the biological method of delignification using lignin degrading bacterial isolates in place of chemical delignification.

\section{Acknowledgment}

Authors are highly grateful to the Director, ICAR-Central Research Institute for Jute and Allied Fibres, Barrackpore, Kolkata for providing necessary facilities and financial support for the study.

\section{References}

Abd-Elsalam, H.E. and A.A. El-Hanafy: Lignin biodegradation with ligninolytic bacterial strain and comparison of Bacillus subtilis and Bacillus sp. isolated from Egyptian Soil. Am-Euras. J. Agric. Environ. Sci., 5, 39-44 (2009).

Bandyopadhyay, S.B. and N.G. Sinha: An airflow method for the determination of the fibre fineness of jute and mesta. J. Text. Inst., 59,148-151 (1968).

Chakraborty, A., D. Sarkar, P. Satya, P.G. Karmakar and N.K. Singh: Pathways associated with lignin biosynthesis in lignomaniac jute fibres. Mol. Genet. Genom., 290, 1523-1542 (2015).

Chang, H.M. and K.V. Sarkanen: Species variation in lignin- Effect of spices on the rate of kraft delignification. Tapp., 56, 132-134 (1973).

Chattopadhyay, L., B. Majumdar, S.P. Mazumdar, A.R. Saha, R. Saha and S. Barai: Use of bacterial endospore with longer shelf-life in improved retting of jute. J. Environ. Biol., 40, 245-251 (2019).

Crawford, D.L. and R. Muralidhara: Bacterial extracellular lignin peroxidase. United States Patent 5200338 (2004).

Das, S., B. Majumdar and A.R. Saha: Biodegradation of plant pectin and hemicelluloses with three novel Bacillus pumilus strains and their combined application for quality jute fibre production. Agric. Res., 4,354-364 (2015).

Das, S., B. Majumdar, A.R. Saha, S. Sarkar, S.K. Jha, S.K. Sarkar and R. Saha: Comparative study of conventional and improved retting of jute with microbial formulation. Proc. Natl. Acad. Sci., India, Sect. B Biol. Sci., 88, 1351-1357 (2018).

Del Rio, J.C., J. Rencoret, G. Marques, J. Li, G. Gellerstedt, J. JimenezBarbero, A. T. Martinez and A. Gutierrez: Structural characterization of the lignin from jute (Corchorus capsularis) fibers. J. Agric. Food Chem., 57, 10271-10281 (2009).

Falade, A.O., U.U. Nwodo, B.C. Iweriebor, E. Green, L. V. Mabinya and A. I. Okoh: Lignin peroxidase functionalities and prospective applications. Microbiol. Open, 6, 1-14 (2016).

Grishanov, S.A., R.J. Harwood and I. Booth: A method of estimating the single flax fibre fineness using data from the Laserscan system. Ind. Crops Prod., 23, 273-287 (2006).

Huang, X., N. Santhanam, D.V. Badri and W.J. Hunte: Isolation and characterization of lignin-degrading bacteria from rainforest soils. Biotechnol. Bioeng., 110, 1616-1626 (2013).

Hussain, M.A., M.E. Huq, S.M. Rahman and Z. Ahmed: Estimation of lignin in jute by titration method. Pak. J. Biol. Sci., 5, 521-522 (2002).

Kamali, M. and Z. Khodaparasat: Review on recent developments on pulp and papermill waste water treatment. Ecotoxicol. Environ. Saf., 114, 326-342 (2015). 
Kumar, V., P. Dhall, S. Narithani, A. Kumar and R. Kumar. Biological approach for the treatment of pulp and paper industry effluent in sequence batch reactor. J. Bioremed. Biodeg., 5, 218 (2014).

Kundu, A. and B. Majumdar: Optimization of the cellulase free xylanase production by immobilized Bacillus Pumilus. Iran. J. Biotech., 16, 273-278 (2018).

Kundu, A., D. Sarkar, N.A. Mandal, M.K. Sinha and B.S. Mahapatra: A secondary pholic (bast) fibre-shy (bfs) mutant of dark jute (Corchorus olitorius L.) develops lignified fibre cells but is defective in cambial activity. Plant Growth Regul., 67, 45-55 (2012).

Magalhaes, D.B., M.E.A. de-Carvalho, E. Bon, J.S.A. Neto and S.H. Kling: Colorimetric assay for lignin peroxidase activity determination using methylene blue as substrate. Biotechnol. Tech., 10, 273-276 (1996).

Meshram, J.H. and P. Palit: On the role of cell wall lignin in determining the fineness of jute fibre. Acta Physiol. Plant, 35, 1565-1578 (2013).

Niku-Paavola, M.L., L. Raaska and M. Itvaara: Detection of white-rot fungi by a nontoxic strain. Mycol. Res., 94, 27-31 (1990).

Parmer, D. and E.L. Schmidt: Experimental Soil Microbiology. Burges Publication Company, USA, Minneapolis. Minn., (1966).

Pease, E.A., S.D. Aust and M. Tien: Heterologous expression of active manganese peroxidase from Phanerochaete chrysosporium using the Baculovirus expression system. Biochem. Biophys. Res. Commun., 179, 897-903 (1991).

Pointing, S.B.: Qualitative methods for the determination of lignocellulolytic enzyme production by tropical fungi. Fun. Divers., 2,17-33 (1999).

Renugadevi, R., M.P. Aryyappadas, P.H. Preethy and S. Savetha: Isolation, screening and induction of mutation in strain for extracellular lignin peroxidase producing bacteria from soil and its partial purification. J. Biol. Res., 4, 312-318 (2011).
Roy, G., G.K. Bhattacharya, S. Sengupta and M. Mukherjee: A new electronic fibre bundle strength tester for jute. J. Inst. Eng. (India), 89, 10-13 (2009).

Ruiz-Duenas, F.J. and A.J. Martinez: Microbial degradation of lignin: How a bulky recalcitrant polymer is efficiently recycled in nature and how we can take advantage of this. Microb. Biotechnol., 2, 104177 (2009).

Sengupta, G. and P. Palit: Characterization of a lignified secondary phloem fibre-deficient mutant of Jute (Corchorus capsularis). Ann. Bot., 93, 211-220 (2004).

Sharma, H.S.S.: Effects of the application of chemical additives to desiccated flax on retting. Biotechnol. Lett., 8, 219-223 (1986).

Shoham, Y., Z. Schwartz, A. Khasin, O. Gat, Z. Zosim and E. Rosenberg: Delignification of wood pulp by a thermostable xylanase from Bacillus stearothermophilus strain T-6. Biodegradation, 3, 207-218 (1992).

Storm, P.F.: Identification of thermophilic bacteria in soild waste composting. Appl. Environ. Microbiol., 50, 907-913 (1985).

Tsutsumi, Y., K. Sakai and H. Imamura: The difference of reactivity between syringyl lignin and guaiacyl lignin in alkaline systems. Holzforschung, 49, 423-428 (1995).

Tuomela, M., M. Vikman, A. Hatakka and M. Itavaara: Biodegradation of lignin in a compost environment: A review. Bioresour. Technol., 72, 169-183 (2000).

Wong, D.W.S.: Structure and action mechanism of ligninolytic enzymes. Appl. Biochem. Biotechnol., 157, 174-209 (2009).

Woo, H.L., T.C. Hazen, B.A. Simmons and K.M. DeAngelis: Enzyme activities of aerobic lignocellulolytic bacteria isolated from wet tropical forest soils. Syst. Appl. Microbiol., 37, 60-67 (2014).

Zhang, Y., Q. Wang, X. Fan and J. Yuan: Structural changes of lignin in the jute fibre treated by laccase and mediator system. J. Mol. Catal. B: Enzym., 101, 133-136 (2014). 